\title{
Feature
}

\section{Cuba's Family Doctor-and-Nurse Teams: A Day in the Life}

\section{Conner Gorry MA}

Nurse Sarait Guarat has Felipe's clinical history out of the file cabinet and on Dr Martha Diaz's desk before he's even through the door. Not that Dr Díaz needs it: Having served 26 years at Consultorio (Family Doctor-and-Nurse Office) \#17 on a leafy street in Havana's Vedado neighborhood, she knows each of her patients by name and their health status essentially by heart. After greeting 91-year old Felipe with the customary kiss on the cheek, Dr Díaz gets down to business, asking after his family, checking up on his diabetes and inquiring about the reason for his visit.

"He's had an upset stomach and some diarrhea, doctora," his wife says from across the room. "That's not good. Let's find out what's going on," responds Dr Díaz, glancing at Felipe with a smile while donning her stethoscope to listen to his heart. After Felipe is weighed by Sarait, a nurse with 25 years' experience in Cuban primary care, Dr Díaz takes his blood pressure and commends him for his healthy $110 / 70$.

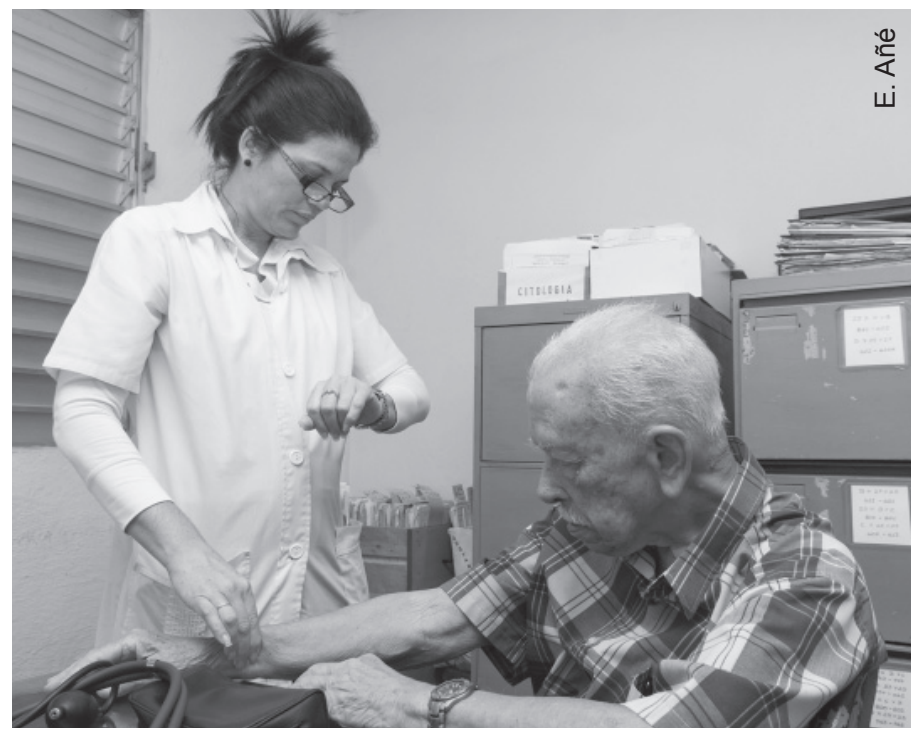

Dr Díaz - known as Doctora Martica to her patients and neighborslowers her voice as she speaks directly with Felipe, inquiring about the frequency and consistency of his stools, when and what he last ate, and reminding him about possible contraindications with his prescription medicines. When he responds that they always boil their drinking water, his Doctora takes the opportunity to test the elasticity of his skin and explain the importance of staying hydrated, boiling all drinking water, and of proper nutrition (including safe food handling and preparation). She contextualizes her response for his preexisting diabetes. When it comes to detailing the suggested treatment and followup-rehydration salts with instructions on proper preparation, a toast and broth diet for the next 24 hours, a folic acid supplement for healthy cell production-Dr Díaz shifts her gaze to Felipe's wife to ensure she's listening, all the while keeping a hand on her patient's shoulder.

From four-year old Gabriela, accompanied by her dad, to 91-year old Felipe, the doctor-and-nurse team at
Consultorio \#17 exemplify the philosophy underpinning family medicine in Cuba: improving population health is possible with a community-, family- and person-based preventive approach that accounts for social determinants, applying pharmaceutical and other therapies when indicated. Shared responsibility for the biopsychosocial health status of both individuals and the community as a whole is another principle evident at Consultorio \#17, demonstrated by the efficiency with which Dr Díaz and nurse Guarat multitask and work together during each consultation, but also in their careful instructions and observations to parents and caretakers. The patience, empathy and humanism with which these two health professionals talk with and treat their patients-regardless of age, gender, sexual orientation, skin color, disability or condition-are additional hallmarks of the Cuban approach. Referring to each patient by name, looking them in the eye, laying on a kind hand, speaking to them directly, observing bioethical standards, and providing the time and space for each patient to describe their condition and talk about changes in their lives-these elements underscore the mutual respect and responsibility for health implicit in the provider-patient relationship in this consultorio.

\section{How Cuba's Community-Based Care Works}

In Cuba, a nation of 11 million people with a universal health system, the consultorios, or family doctor-and-nurse offices, located in every neighborhood across the country, form the backbone of primary care. Each office is staffed by a family doctor-and-nurse team responsible for a catchment area of up to 1500 people. National coverage is provided by the 12,833 family doctors in Cuba (one for every 127 inhabitants, 2015 data), who, under the country's universal education system, graduate debt-free and are required to complete a two-year residency in comprehensive general medicine (family medicine) before pursuing a second specialty. When the Family Doctor-and-Nurse Program was piloted in Havana in 1983, physicians lived above the consultorios to better provide integrated, comprehensive primary care based on easy access and an annual neighborhood health assessment.

The family doctor-and-nurse model was then extended throughout Cuba, reaching the most remote areas, until finally reaching the whole population. As the program grew, it became impractical to locate every doctor's residence in the same building as the consultorio. Although this model is still found in many neighborhoods, today some physicians, like Dr Díaz, live within a block or two of their consultorio instead of directly above it.

Each consultorio refers patients to and is supervised by a multispecialty, multiservice clinic called a polyclinic. Also based in the community, polyclinics offer diagnostic procedures, laboratory testing, dentistry, physical therapy, natural and traditional medicine consultations and primary care specialties such as internal medicine, pediatrics, psychiatry and ob-gyn. Each of Cuba's 451 polyclinics supervises a maximum of 30 consultorios and provides services for between 20,000 and 60,000 patients. Accredited consultorios and polyclinics 
Feature

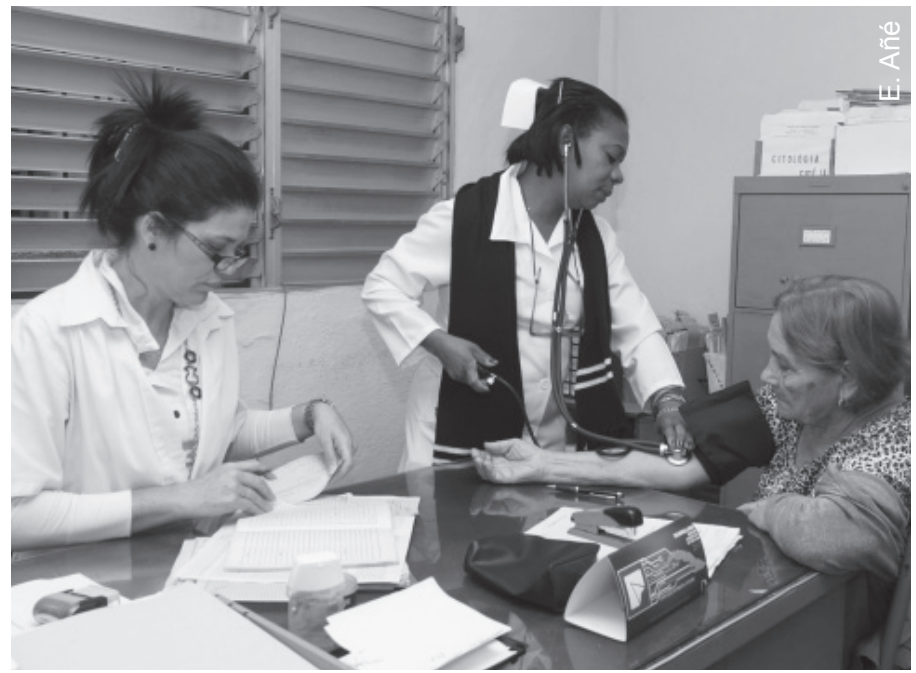

serve as clinical teaching sites for Cuban and increasingly, foreign, medical students, while also providing functions that support population health including: dissemination of health promotion messages and public health advisories, community health statistics reporting, and linkages with secondary and tertiary services in the national health system. In Vedado's Consultorio \#17 for example, the waiting room displays schedules for dental, internal medicine, pediatric and obstetric doctor visits, as well as psychological counseling. Posters depict HIV and STI prevention, proper oral hygiene, signs and symptoms of vector-borne diseases (Zika, dengue, and chikungunya), healthy nutrition guidelines and use of natural and traditional medicines (including their applications, preparation and dosage). There are also data from the most recent dispensarización, or CARE (for Continuous Assessment and Risk Evaluation), a system of classifying consultorio patients for personalized followup (See Table).

\section{Evaluating Community Health to Improve Health}

The CARE process, which is dynamic and ongoing, and an annual neighborhood analysis together provide a snapshot of the health of each community and the individuals within it. These tools serve as the evidence base for family doctors (and inform the health analyses of their corresponding polyclinics) to tailor services to the specific needs of their catchment area. Although national health priorities, programs, and guidelines are established and implemented by Cuba's Ministry of Public Health (MINSAP), regular analyses of disease burden, risk factors and social determinants of health at the local level empower primary care providers to prioritize and tailor health promotion messages and disease prevention, diagnosis and treatment, and rehabilitation services.[1] These assessments categorize individuals in four groups:

Group I: Apparently healthy individuals

Group II: At-risk individuals who may develop health problems due to risk exposure at home or work

Group III: Sick individuals, including those with chronic, communicable or non-communicable diseases

Group IV: Disabled or otherwise incapacitated (temporarily or permanently) individuals suffering from disruption of their motor, functional, sensory or mental capacities
Continuous Assessment \& Risk Evaluation, 2016, Consultorio \#17

\begin{tabular}{|l|l}
\hline Variable & Value
\end{tabular}

\section{Demographic data}

\begin{tabular}{|l|l|}
\hline Total population in catchment area $(n)$ & 1151
\end{tabular}

Male population (n) 540

\begin{tabular}{|l|l|} 
Female population $(n)$ & 611
\end{tabular}

Families in catchment area (n) $\quad 344$

\begin{tabular}{l|l|}
\hline Aged $<1$ year $(\%)$ & 0.3
\end{tabular}

Aged $1-9$ years $(\%) \quad 5.0$

\begin{tabular}{l|r|} 
Aged $10-14$ years $(\%)$ & 3.4
\end{tabular}

Aged $15-29$ years $(\%) \quad 15.0$

\begin{tabular}{|l|r|}
\hline Aged $30-49$ years $(\%)$ & 21.0 \\
\hline
\end{tabular}

Aged $50-69$ years $(\%) \quad 26.8$

\begin{tabular}{l|l|} 
Aged $70-79$ years $(\%)$ & 14.9 \\
\hline
\end{tabular}

Aged $\geq 80$ years $(\%) \quad 13.7$

\begin{tabular}{|l|l}
\hline Education & $\%$ \\
\hline
\end{tabular}

No schooling $\quad 0.9$

\begin{tabular}{|l|l|} 
Completed elementary school & 3.1
\end{tabular}

Some elementary school $\quad 1.1$

\begin{tabular}{l|l} 
Middle school & 6.4
\end{tabular}

$\begin{array}{ll}\text { High school } & 7.4\end{array}$

\begin{tabular}{|l|r|}
\hline Technical degree & 24.2
\end{tabular}

University degree $\quad 57.0$

\begin{tabular}{l|l} 
Risk groups & $\mathbf{n}(\%)$
\end{tabular}

Group I 358 (31.1)

\begin{tabular}{l|l|} 
Group II & $212(18.4)$
\end{tabular}

Group III 518 (45)

\begin{tabular}{l|r} 
Group IV & $24(2.1)$
\end{tabular}

Unclassified 39 (3.4)

Chronic non-communicable diseases $\quad$ n

$\begin{array}{ll}\text { Hypertension } & 225\end{array}$

Asthma $\quad 83$

Heart disease $\quad 48$

\begin{tabular}{l|r} 
Type I diabetes & 15
\end{tabular}

Type II diabetes $\quad 59$

\begin{tabular}{|l|l|}
\hline Obesity & 63
\end{tabular}

Dyslipidemias $\quad 46$

\begin{tabular}{l|l} 
Smoking & 353
\end{tabular}

Alcoholism 4

Cancer $\quad 2$

Sexually transmitted infections $\quad 11$

Cerebrovascular disease $\quad 4$

Source: Consultorio \#17, Havana, 2017

Categorizing individuals thus enables their providers to design followup and treatment plans. Dr Díaz and nurse Guarat, like all family doctors and nurses in Cuba, are required to conduct assessments of individuals in Group I once a year, in Groups II and IV twice annually, and in Group III three times.[2] "One of the reasons I love family medicine is that it allows you to customize care for each person," says Díaz. "Of course there are national best-practice guidelines we follow, but I can't go six months without visiting my Group IV patients—disabled and homebound people. We visit them at least three times a year. And if one of our patients in Groups I, II, or III experiences a change in their health, we'll see them more often than required-either here in our office or in their homes." Data collected during these assessments are recorded on a standardized Family Health History form [In Cuba, most clinical 


\section{Feature}

records are kept in hard copy and maintained in bound books; a pilot project to digitize medical records at Hermanos Ameijeiras University Hospital in Havana will launch soon-Eds.].

The form assigns each patient a unique clinical history number and collects general and demographic data including: name, address, age, gender, birth date, educational level and type of work or employment. Health problems, including risk factors and chronic conditions, are documented with pertinent observations resulting from each consultation, as well as on the quality of their living conditions (e.g., date of construction of their home and whether or not it is structurally sound), a factor directly linked to health and well-being. The form also classifies families as functional, at risk of dysfunction (and why), or dysfunctional, allowing providers to better explore and identify other adverse social determinants of health, providing a baseline for a continuum of care-another hallmark of Cuba's community-based model. During the consultation itself, each patient is then classified as healthy or not.The most common conditions and illnesses seen at Consultorio \#17 include asthma, food- and water-borne diarrheal diseases, diabetes, hypertension and cardiovascular disease.

An important function of the neighborhood health diagnosis is to identify how many pregnant women reside there. According to national guidelines set by MINSAP in conjunction with Cuba's National Maternal-Child Health Program (PAMI), pregnant women receive a full intake exam by the 9th week of pregnancy, and a minimum of 12 antenatal visits, as well as a battery of standard tests (with the expectant mother's family doctor-and-nurse team conducting in-home consultations when a visit is missed, accompanied by the patient's obstetrician when warranted). These standards have helped lower Cuba's infant mortality from 11.1 per 1000 live births in 1989 to 4.3 per 1000 in 2015.[3,4]. Nevertheless, health authorities on the island are acutely aware of the impending calamity presented by Cuba's low fertility rate (1.7 children per woman in 2015 , with an even lower crude reproductive rate, daughters per woman, of 0.83 ), and high life expectancy of 78 years.[4] If the greying of the population continues without a concomitant increase in births, deaths are projected to outpace births in a decade.[5]

MINSAP/PAMI-designed and UNICEF-approved Infant Health Records (Carnet de Salud Infantil) are initiated by the corresponding maternity hospital upon each live birth and maintained by the mother and child's primary care team (family doctors and nurses, gynecologist-obstetricians, and pediatricians) from then on. Each detail of the pregnancy and birth are recorded in this booklet. These include: demographic data; congenital conditions; results of physiological and neurological studies; birth complications; illnesses during pregnancy, birth and/or puerperium; gestational age at birth; and whether birth was at term, preterm ( $<37$ weeks) or post-term ( $>41$ weeks). Records for newborns show birth weight (noting if $<2500 \mathrm{~g}$ ), cranial circumference, body length, at what minute the newborn took its first breath and whether the infant showed signs of any congenital disease or condition. Before the baby is released from the hospital, a battery of physical exams is conducted and whether the new mother is exclusively breast feeding is documented.[6]

Once mother and baby are released from the hospital, the family doctor-and-nurse team (in close coordination with ob-gyns, pediatricians and other specialists as required) assume postnatal followup, maintain vaccination schedules, and monitor the baby's physical and mental development. On a home visit with new mother, Akate Castellón, Dr Díaz explained to MEDICC Review that national guidelines require weekly consultations in the first month of the infant's life, office visits every 15 days from $1-2$ months old, and twice monthly visits (one office and one home) when the baby is between 2 and 12 months old. After being welcomed into the home Akate shares with her mother and grandparents and accepting a cup of the black, sweet coffee on which Cubans thrive, Dr Díaz sits on the floor with 8-month-old Darling and her 25-yearold mother to test motor and ocular responses and whether the baby can sit without support-standard tests for babies at this stage of development. Dr Díaz encourages Darling to grasp at a block held just out of reach, keeping up a conversation with Akate, during which she confirms that she is still breastfeeding, asks what food supplements her breast milk, and inquires after any new developments in the baby's health since the last visit.

As the coffee is served in tiny flowered cups, Dr Díaz enquires about the health of Akate and other family members-four generations living in one household is not uncommon in Cuba and underscores the need for family doctors' knowledge and clinical skills to address health issues over the life span. While Dr Díaz attends to her grandfather, 83-year old Orlando Azoy, Akate reviews Darling's Infant Health Record, specifically the National Vaccination Guidelines for infants and children (Cuban children are vaccinated against 13 childhood diseases) and the National Nutritional Guidelines for Children under One. Dr Díaz takes Orlando's blood pressure-“130 over 75. Divine!"-and proceeds to conduct flexibility and strength tests. No one else in the household has had any change in their health status, so Dr Díaz gets ready to move on to her next visit, to an elderly, homebound patient with Alzheimer disease. But first, she reminds Akate that Darling will be due for her measles, mumps and rubella vaccine in four months.

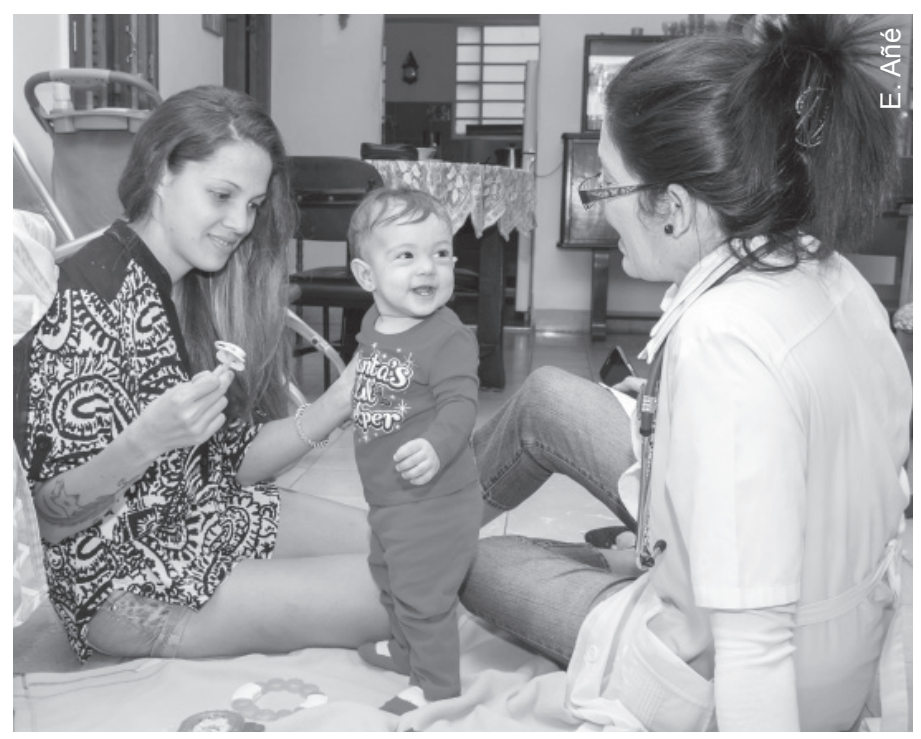

\section{Identifying Problems \& Forging Solutions}

As chance would have it, today is the monthly meeting of Consultorio 17's Basic Work Group. Comprising the family doctor-and-nurse teams within a polyclinic catchment area, plus an internist, pediatrician, ob-gyn, psychologist, nutritionist and 
social worker, the Basic Work Group is responsible for diagnosing and treating patients, but also for evaluating the services provided and problems in the polyclinic's catchment area. These monthly meetings-attended by the 13 family doctor-and-nurse teams linked to the Moncada Polyclinic and chaired by a nurse supervisor and the polyclinic's Deputy Director-analyze the work of the past month, evaluate family doctor-and-nurse team performance and discuss the progress of various health promotion and prevention initiatives. The meetings also include teaching sessions on a health theme pertinent to their catchment area and updates on vector control (Cuba has an ongoing national program for control, diagnosis and treatment of vector-borne diseases, including Zika and dengue).[7]

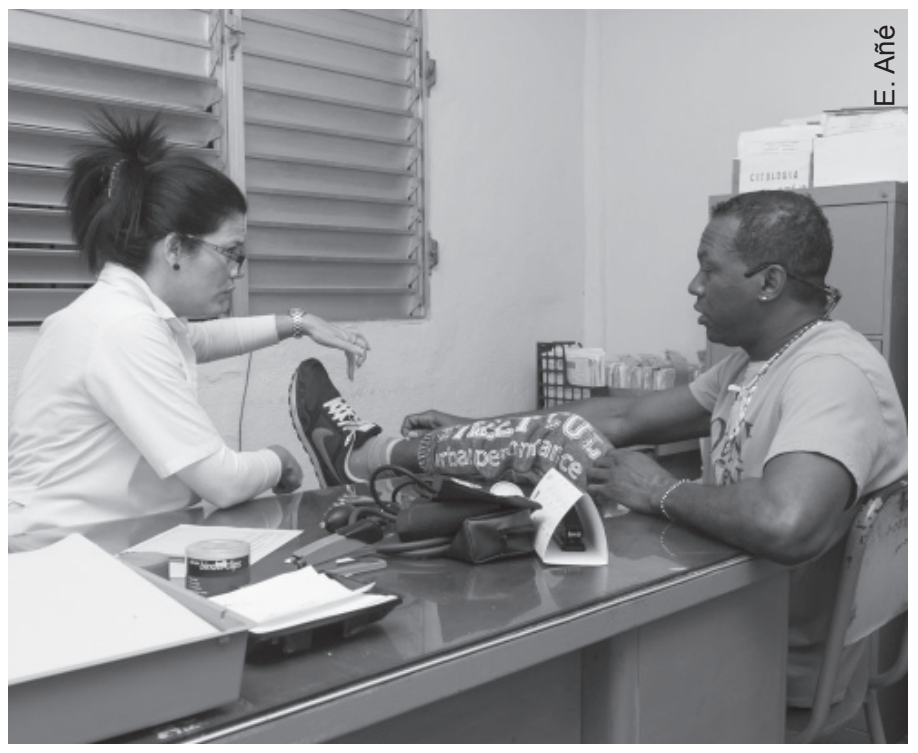

Dr Díaz is following up on a 53-year old patient's progress in physical therapy for her chronic lower back pain when the head of vector control for the area comes in to update the doctor-and-nurse team about the week's mosquito control efforts. He supplies them with specific addresses where no one was home for inspection of standing water and other elements increasing probability of mosquito proliferation. He also reported on homes, offices and outdoor areas inspected that might be at risk due to environmental and/or structural factors, information to be passed on to the Basic Work Group at today's meeting. Shortly thereafter, the nutritionist who sees all pregnant women in Consultorio 17's catchment area stops in to double-check the information she needs to provide at the meeting. Between patients and conversations with members of the Basic Work Group, Dr Díaz answers the phone to provide followup, consult with other primary care providers, and talk to her son. Meanwhile, nurse Guarat shuttles between the examining and waiting rooms, pulling clinical history files and otherwise streamlining the intake process.

Dr Díaz speaks frankly about the challenges facing family doctors in Cuba's current economic and social context: "The fact that people are more able to travel abroad complicates our work. We do neighborhood-wide active screenings, and if people are out of the country, it makes it more difficult," she says, referring to 2011 reforms that dropped the exit permit requirement for Cubans, along with other adjustments facilitating international travel. Increased mobility within the city causes similar challenges for vector control. "We had 16 families move out of our catchment area last year and some of them didn't let us know. We have to be attuned to this new mobility and how it affects the local health picture." Neither Dr Díaz nor nurse Guarat has served overseas [Cuba currently has over 20,500 doctors working in public health systems in 62 countries-Eds.], ensuring stability and continuity of service to their own practice population.

Consultorio \#17, like many across Cuba, is a teaching clinic. Cuba's medical education curriculum places students in clinical settings in their third year. These students include foreign students from the world over, and not all Cuban patients want to be examined by a foreign practitioner. Dr Díaz, with 19 years of teaching experience, explains: "We have a medical culture that promotes a warm, affectionate doctor-patient relationship: greeting patients by name and with a kiss on the cheek, holding their hand and having them sit beside rather than across the desk from us. This establishes an atmosphere of trust and respect between patient and provider." It's cultural affinity more than anything else, she explains, observing that this can't always be taught.

The trust and affection between Dr Díaz, nurse Guarat and their patients is obvious and the environment in their office is upbeat and welcoming. Given the stress under which all health professionals work-especially in Cuba where resource scarcity defines most sectors and the entire health system is facing an aging population and the attendant increased care needs (which Dr Díaz singles out as 'one of our greatest challenges')- this is no small accomplishment. "I love what I do and this enthusiasm is contagious," she explains. Upon further probing, she elaborates: "When my son was 11, he was in a coma for 21 days. That turned the tables on me. Suddenly, I was a parent with a child between life and death, not a doctor. I learned what that felt like, and was determined to incorporate that insight into my practice. The doctors told me he would never talk again, but he not only relearned speech, he graduated near the top of his high school class. He's the love of my life and keeps me motivated to treat my patients to the best of my ability every day." - 1 -

\section{REFERENCES \& NOTES}

1. Keck WC, Reed GA. The curious case of Cuba. Am J Public Health, 2012 Aug;102(8):e13-22

2. Ministry of Public Health (CU). Programa del médico y la enfermera de la familia, 2011. Havana: Ministry of Public Health (CU). 2011. Spanish.

3. ACN. Cuba reduces infant mortality rate to 4.3 in 2016. ACN [Internet]. 2017 Jan 4 [cited 2017 Jan 19]. Available from: www.cubanews.acn.cu/science/6241 -cuba-reduces-infant-mortality-rate-to-4-3-in-2016

4. Ministry of Public Health (CU). Anuario Estadístico de Salud, 2015. Havana: Ministry of Public Health (CU). 2016. 208 p. Spanish.

5. AFP. Graying Cuba approves plan to boost birth rate. AFP. [Internet]. 2014 Oct 27 [cited 2017 Jan 24]. Available from: www.yahoo.com/news/graying-cuba -approves-plan-boost-birth-rate-175641018.html?ref=gs

6. Cuba has a national skin-to-skin or 'kangaroo' care program and 57 UNICEFaccredited 'Mother-and-Baby Friendly' maternity hospitals, meaning that a high percentage of new mothers are successfully breast feeding upon hospital release. See: Cuba's human breast milk banks in MEDICC Rev, Jan 2014, Vol 16, No 1.

7. For details see: Cuba confronts Zika: All hands on deck in MEDICC Review, Jan-Apr 2016, Vol 18, No 1-2. 